\title{
MIGUEL EGUAL POETA Y TRADUCTOR (II). SONETOS
}

\author{
Pasqual MAS I USÓ Y Javier. EELLON LAHOZ \\ Universitat Jaume I
}

La voluntad frustrada del intelectual

La figura de Miguel Egual es una muestra de la situación conflictiva del intelectual en las primeras dócadas del siglo xvill. A ello se añaden sus deseoncertantes peculiaridades biográficas que reflejan el espíritu contradictorio de un intelectual necesitado de sumar conocimientos para discernir entre ellos, y alejado de los centros de difusión cultural. No es cxtraño, por tanto, la abundancia de misivas recogidas en el particular archivo mayansiano: el reformista valenciano representa todo aquello que. Miguel Egual había descado conseguir para sí y, en otra vertiente, su vínculo más imporlante con el entorno intelectual de la urbe.

Un rápido examen de las cartas de Miguel Egual testifica que las primeras, transcurridas desde el inicio de la década de 1730 (justamente coincidiendo con la publicación de las Dectamaciones), son las que translucen una mayor inquietud hacia la problenática cultural efectiva. Animarto por la impresión de su traducción, auxiliado por la mano maestra de Mayans e, incluso, con problemas de censura, cl autor crec ver en sí mismo la plasmación de las controversia culturales de su famoso amigo, y contempla un horizonte personal no alejado del mercado de la letras de la ciudad.

En este lustro se lamenta constantemente de su aislamiento de Oliva, con alusiones literarias a su situación, como cuando habla de klograr salir de este 
Argel» (carla VII), o su comparación, ya citada, con el destierro sufrido por Ovidio (carta XIII). En una carta de 1734 deste Pego (carta XV), Miguel Linual realiza st llamamiento más directo a Mayans: ya a sus 53 años, con tres lijos y uno en camino, su narcha a la corte se ve lrenada, como él asegura, no por "pusilaumidarl de ánimo valenciano», sino portus necesita ejercer en ese lugar una labor rue le repercuta beucficios económicos con los que sostener a su familia, para lo cual solisita la intervención de Mayans ante Bermúdez.

Miguel figual somoce bien, siu duda, la ciudad de Valencia, clonde realizó sus procos estudios, pero, a la vez, se vislumbra en sus palabras la proyecoión de un idteal que sólo se cumple en la confrontación entre su lugar de residencia (Cliva, Pego) y el centro cultural valenciano. En el primero, dice vivir «a lo rústico», sin posibilidad de «lratar de letras», pues los lusgareños "párecen aborrecerlas» e, incluso, se lamenta de haber olvidado hablar «en español» (carta IX). Por el contrario, en Valenciat cree ver «la conlinua racionalidad de la corte» (carta XIX), esto es: el único lugar donde puede llevar a valoo su carrer'a literaria.

La frusilración intedectual del antor se centra sincomálicannente, ya no ela la corte madrileña, que había subyugado a tantos profesionales de clases merlias a finales del siglo anterior, sino en el eje del nuevo petisamiento enya cabeza visible es Milyans. I as obras que, perentoriamente, solicita a Mayaus, reflejan un conocimiento, deste su destierro de las novedades importantas de las que se nutricron los reformistati valencianos: distintos libros de Mayans, piezas de: Bordazar, la Vieda de Manuel Martí, la Cramática do Nebrija, etc.

Nos encontramos pues, dentro de las limitaciunes anibuidas a un humilde oficial de Ayuntaniento cuya labor intelectual es más una pretensión quet una realidat, ante. ura nueva artitud no desteñable desde una perspentiva histórica. Sabido ess. por los estudios literarios, gue tanto o más sintonnáticos

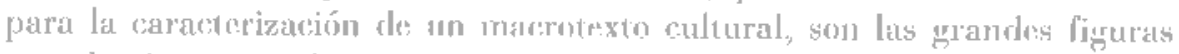
que dominetri una época, como sus epígonos: éstos llevan al extremo los logros de aduellos, en una dialécova de copia/originalidad, que permite vislumbrar, de un modo más reptero, la dinánica ideológica de una etapa bistórica determinada.

Así pues, el examen de las actitudes de Miguel Egual ejemplifica la extensión de un movimiento renovador, cuyo epjicentor se localiza en Valenciu, y que alcanza a amplios sectores sociales, conno lo demuestra la propia caracteriza-

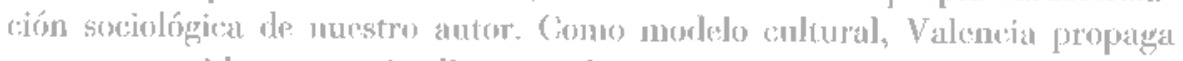
unas mevas ideas (pue cristalizatus en el movimiento de los novatores, amnque conviene no olvidar un problema lingüístico que trataremos en el punto 
siguiente, y que imposibilita caer en maniquésmos radicales como el enfrentar rentro versus periferia.

No obstante, volviendo a la idea original del presente capítulo, los resultados textuales en Miguel Egual distan bastante de este alentador panorama trazado a partir de su relación epistolar: las Deckmaciones, corresponden a wa vertiente basoquista, inserta en el tejiclo social dieciochista a lo largo de todo el siglo, y al que deberám enfrentarse los ilustrados como exponente de su "despotismo».

La falta de consistencia de vua ideología, imputable en el presente caso a la avidez culturalisia del autor, pentiente más de las novedades que de su incorporación a un sistena lógico de valores históricos, señala ese continuo vaivén entre las estentóreas prefensiones del reformismo y la consceución de rextos anclarlos en el prasado.

\section{La lengua y el problema de la tradución.}

En la época de: Mayans, uno de los temas centrales que los reformistas tomarán como propios es el estudio de la longua castellama.

Ia larea de la iraducción se ha de incluir en la preocupación explícila expresada en torno a la problemática lingüística que dosarrollaron los seguidores del gran intelectual de Oliva, sin desteñar, por supuesto, una posterior derivación literaria a la que nos reteriremos más tarcle.

Tras los vericuetos setóricos a los que se vio somedido el sistema lingüístico castellano durante la época harroca, y solore los que no hace falta insistir, cl clasicismo pretendió retornar al espríritu de un mecanismo lingüístico que privilegiasa la fumción commicaliva en detrimento de la sacralización lormalista a la yue habím recurrido los conceptistas. Esta, al menos, es la consecuencia práctica que se puede exprace de la lectura que los primeros neoclásicos realizarom al Siglo de Oro, y, por otra parte, no es sino la consecución de un instrumento válido para la propagación, por cualquicra de las variedades diafásicas rle la lengua, de los nuevos ideales y su implantación social.

En la comespondencia ontre nuestro autor y Mayans se menciona un importante número re obras mya materia es, precisanente, la invesigación lingüústica bien desde una perspectiva diacrónica o sincrónica: la Ortografíct de Antonio Bordazar; la importante obra de Cregorio Mayans Orígenes de la lengua espreñola, medianto la cual, la disposición reformista se remonta a los esta- 
dios primigéneos de la lengna con vistas à recuperar la purezal de la expresión, "corrompidal" por los juegos barroguistas solore al significante; El Orador Christiano, del mismo escritor, que lrata sobre retórica de la comunisación oral, como lo harán ofras obrgs importantes del Xyli, entre las que pochríanos

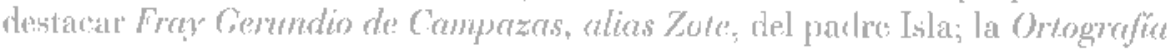
castellana de Nebrija, sacada a la luz y comentada por el propio Mayans, y que, dentro de la corriente dieciochista que pretende incorporar los trabajos

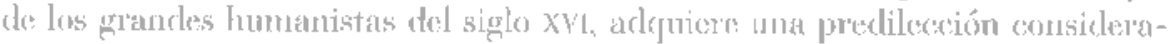
ble (y sobre la que Migued Lignal realiza una curiosa redlexión eu rorno a la

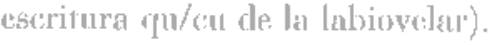

¿Qué dimensión pose lis traducción cu el espacio de la prescaparión lin-

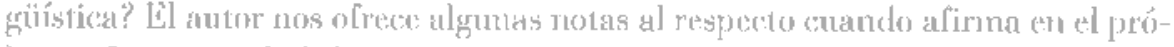

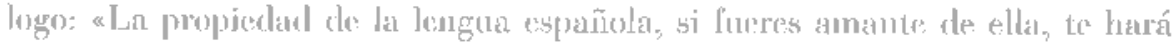

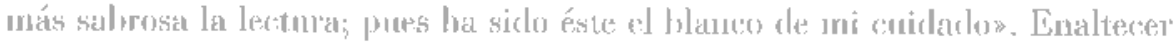
y cuider la lengua de: Ilegada patrece ser el propósito último de su tratbajo. Pero

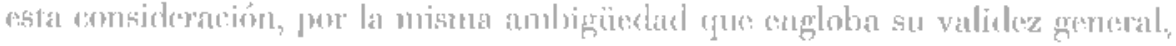

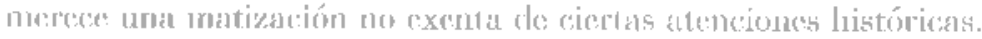

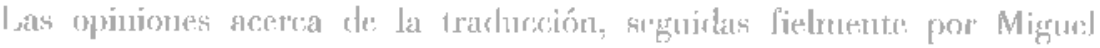
Regual, contenidas en su iutroducción a las Deedemaciones, contribuyen a reali-

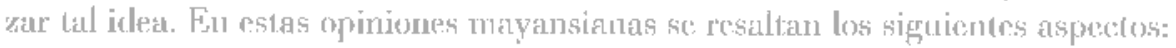

a) La lectura de Ins texus dehe Ilevarse a vabo descle mo prisma cultural soncordante con la éporat an que se rcaliza la traducción. Si la literaturá, como

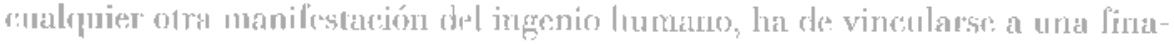

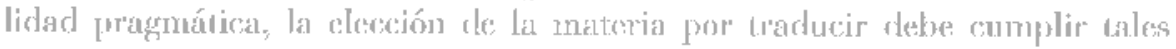

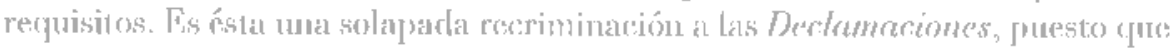

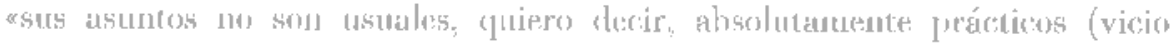

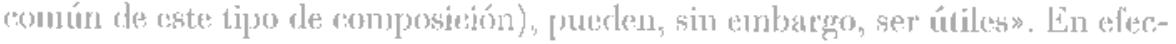

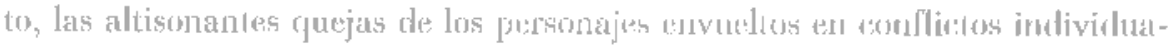

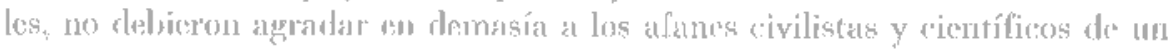
neoclásico unilitanto como Mayans.

b) I a dualidar forma/contenido, chya controversia en al canpon da la trat-

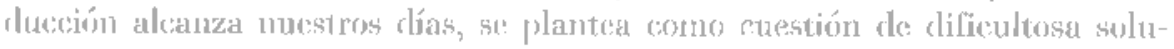
aión. Para Gregorio Mayans es indudable que el trarluctor fija su atención en las correspondencias semánticas entre lenguas y a eflo subordina la expresión significante, con el preligro acuriante de que, "1al vez se descuida en ésta».

c) Uno de los grandes problemas por resolver se lunda ch el conocinniento exacto de la lengua de partida ya no únicamente desde una persperetiva nor- 
mativa, sino en su función poética (esto es: las condiciones del sistema literario en que dicha lengua se incluye), para «saber aplicarle la correspondencia debida, de que es capaz la lengua en que se traduce». La modernidad de tal aseveración rebasa los límites de la presente introducción; sólo queremos anotar que, en la actualidad, uno de los puntos de discusión en las tareas de traducción radica, precisamente, en la necesaria translación entre sistemas estéticos (la literatura puede considerarse un sistema complejo cuya base fuera la forma lingüística), y no en la búsqueda de similitudes basadas en significados exclusivamente lingüísticos.

d) Por supuesto, Mayans admite la existencia de «ciertas palabras más expresivas, que las de otro cualquiera, y ciertos modos de decir muy peculiares», cuya transposición a otra lengua resulta prácticamente imposible; ahí entra el ingenio y conocimiento de la potencialidad expresiva de ambos idiomas que debe poseer el traductor.

\section{El rutor frente a su obra}

En el prólogo introductorio a las Declamaciones, Miguel Egual se refiere a éstas, en un habitual ejercicio de humildad, como, «un honesto desahogo de más serias tareas»; un año antes de su publicación, en la carta III, desde Oliva, pide a Gregorio Mayans que el original italiano quede en su poder por si fuera menester realizar alguna corrección dado que, según sus propias palabras, no realizó la traducción con vistas a una futura impresión que viera la luz pública.

Estas manifestaciones responden, sin duda, a un escrúpulo retoricista más que a un sentimiento sincero de inquietudes intelectuales. En sucesivas epístolas, cada vez más próximas a la fecha de edición, Miguel Egual capitaliza el tema su traducción como evento de indudable interés para su rayectoria: le dice a Mayans que si es necesario pagar un doblón de oro para el papel del librero, y así acelerar los trabajos de la imprenta, no lo regatec (carta II); ya vimos algunos problemas que le acaecieron en relación con don José Bermúdez y, además, advierte al librero para que no aparezca el primer pliego, "pues de lo sucedido no se ha de hacer mención por ningún resquicio» (carta VII); insiste en diversas ocasiones a Mayans sobre el estilo inadecuado del prólogo y la dedicatoria que debe encabezar el libro (de tal modo que, según infornación de la carta IV, el prólogo original fue sustituido por otro sugerido por Mayans); se refiere, en términos poco diplomáticos, al «estropeado estómago de ese buen viejo» (carta X), aludiendo a la censura eclesiástica (muy bien podría perso- 
nalizarse en el doctor Alhiñana), que le ordenó retiray dos de las dectanaciones originales, asunto al que: Miguel Egual da una gran importancia.

Estas muestras ejemplifican la cautcla con lat que debemos asutnir sus primeros propósitos. Sus constantes menciones a la tarea de traducir como connibución personal a la fijación y pureza del jdiona, la importancia que set autoconcede como seguidor de una tradición humanística cercana a la do su mastro y protector, imposibilitan interpretar sus intenciones ereativas y lite-

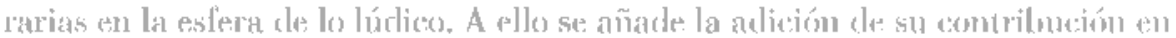

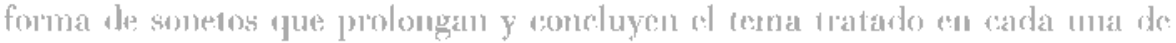
las declamariones, a los gue Mayans define, con el estilo hiperbólion típico de los juicios a las obras de una amistad, como agraves y sentenciosos».

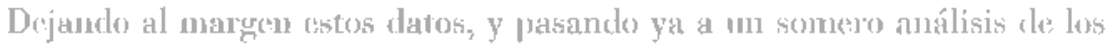
contenidos textuates de las Derkmarionses, laky gue convenir una nota común a todas ellas: lonfusionismo estilístico y significativo. Las distintas pjezats son una analganea de presupuestos ideológicos, nuty a menudo contradiéto-

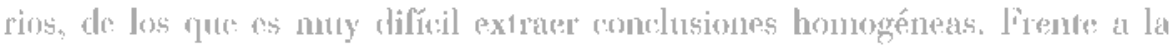
aprología clel heroísmo parriótico se sucesle und críica lunihunda a la viela cortesana y a la xohusmas; junto a la alahanza del príneipe aparese el consepto de la tiranía y lá idea sti generis de la ley natural, ete.

Quizá nna de las constantes en las cue se insiste con mayon gravedad es la interrelación entre la intrahistoria del personaje (sus conflistos y problemas), con la sitnación pública de ka comundad. La transcendencia de la situarión individual a una dimensión social viene recuhionta pou una forma pasional,

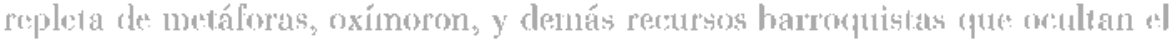
sentido tras el tamiz de una expresión retoricista, simultaneada con un intranto, no disimularlo, de utilizar un estilo «mny llano».

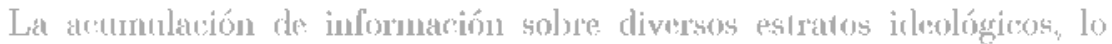
sulicientemente leterogéneos para ser interpretados con precaución, sen sinto-

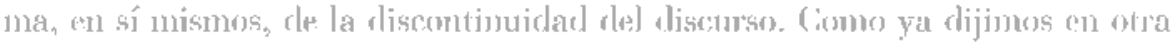
parte de la presente introductión, el epigonismo, y más ubicado en ma etapa historiona de transicióm, no profurdiza on los apartados fundarucontales de la renovación, sino que permanece en los niveles extremos que envuelven lá reclexión crítican.

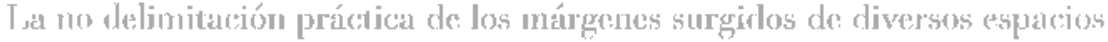

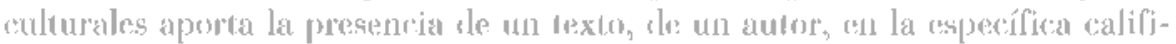

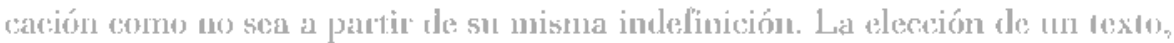
de un autor", en la esperifica labor de la traducsión, wo asgota el candal inter- 
pretativo al que se ven sometidos los resultados de dicha translación. En cuanto yue el sistema literario, como exposición estética de la lengua de comunicación, varía paralelamente a la cosmovisión cultural, la traducción deja de ser un hecho objetivamente valorable y pasa a ser coucstionada cono emblema representativo de unos parúmetros ideológicos. Sus resultados, pues, adquieren validez de creación y como tal deben ser analizados.

Siguiendo este prisma, la obra de Miguel Egual se encuadra en la conflictiva situación del ehumilde» intelectual, ávido de las novedades de los centros de poder, pero incapaz de racionalizarlos a través de un discurso propio. No de otro modo puede evaluarse la atracción hacia los furibundos lamentos de una dama violada, o hacia la pasional reacción de un amigo ultrajado, en un momento en que el equilibrio de la razón trata de recuperar el conocimiento científico de la naturaleza, la sociedad y el pensamiento en sus múliples derivaciones filosóficas.

En este contexto, no es difícil entender las palabras de Mayans, con las que cerramos nuestra introducción, más como una exposición de intenciones que como una realidad palpitante: «de la medida de un dedo se puede colegir fácilmente la grandeza de un colosos.

\section{SONETOS}

\section{I}

Venza al valor tan justo sentimiento: Aquiles llore en lúnebre quebranto. gue rendirse a la pena, en dolor tanto, más que tibiezal, es racional aliento.

Ensénele al Troyano en su tormento, que su brazo ha de ser tertor y espanto, y en vivas expresiones de su llanto, adorne de Patroc lo el monumento.

(Gima pérdida tal, y en el retiro de un vehemonte sentir no comuncro, sea furor, lo que ha de ser suspiro.

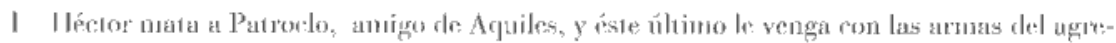

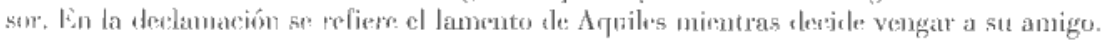

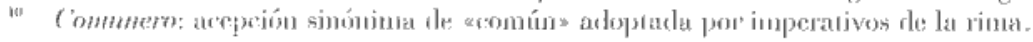


Porque llegar a ser el dolor fiero, sólo tiene lugar, si bien lo admiro, en muerte de un amigo verdadero.

jOh, Agripina infeliz! Severo hado persigue tu inocencia, y fementido se acusa de un insulto cometido, aún de lo irracional impracticado.

El furor de tu hijo concitado del vil Afranio, y con razón temido, hace más implacable lo sentido, pues aún del pundonor se ve agitado.

De Tiburcio y Calvinio la liviana falsedad que le imputan a tu pena, mitigue la congoja que te afana.

Mas, joh, ambición que de maldades Ilena cuanto más te acreditas de tirana, tanto más tu error mismo te condena!

III

Pasmo de Roma, Oráculo divino, archivo del saber, en quien lo humano seguro así lo encuentra, si tirano le amenaza fatal cruel destino.

Tu retórico numen peregrino ¿no fue invencible escudo del romano? ¿Tu acento, no serio por soberano, pautas al Griego, reglas al Latino?

II En la declamación, Agripina intenta justificarse ante su hijo Nerón, de que las acusaciones vertidas contra ella, querer asesinarlo, son [alsas.

" Fementido: falto de fe y palabra. "Concitado: Alterado, conmovido, excitado.

III Gicerón recrimina a su hijo por su comportamiento liviano. En la declamación se dice que no le permitiría «el triunfo de otro laurel que de un pámpano o de una vido. 
¿Acaso de tu hijo la rudeza

puede ser culpa en el paterno afecto?

¿No sabe el orbe todo tu entereza?

Mas, ,ay! que si eres causa de este efecto,

es tan grande del mundo la vileza,

que llegará a achacarte algún defecto.

\section{IV}

¡Oh, fementido Paris! „Así deja

tu infiel amor a Enone despreciada!

¿Qué sentencia dará justificada,

quien de su obligación así se aleja?

Recapacita bien la justa queja

y hallarás tu elección, sin duda, errada;

pues la más sabia acción no es acertada,

si fiera ingratitud es quien la veja.

De Palas, Juno y Venus la disputa

le deja a tu juicio inmortal gloria.

Pero no, que en vileza se transmuta:

que no pucde lograr tal vanagloria,

y sólo entre los brutos se computa,

quien huye al beneficio la memoria.

\section{V}

De la ley del recato enamorada, ¡oh, invencible nutrona!, resistías del más lascivo amor las tiranías, hecha bronce a los filos de su espada.

IV Soneto dedicado al lamento de Enone, celosa por la afrenta amorosa de Paris que se excedió en su tarea de juzgar la belleza de las tres diosas Palas, Juno y Venus, olvidando su comproniso con la Ninfa. En la declamación, Lucrecia, antes de suicidarse para no seguir manchando el honor de su familia al haber sido violada por Sesto Tarquinio, cuenta lo sucedido. Entiéndanse los prejuicios de Luerecia en el contexto del código del honor del siglo Xvir.

$V$ " Matrona: mujer noble, virtuosa y homrada. ${ }^{7}$ Bateria: fortificación. 
Vencer no pudo tu constancia honrada

de los halagos la tenaz porfía,

que a murallas de honor, no hay batería,

que consiga el estrago porfiada.

Tan sólo la violencia del liviano

Tarquinio tus candores atropella:

¡Oh, amor a todas luces inhumano!

Mas, ¡ay, Lucrecia, que naciste bella

y es la hermosura riesgo tan tirano,

que sólo en lo infeliz halla su estrella!

De Mario y Cinna la crueldad impía,

foh, Marco Antonio! tu constancia apura

sir que tanto dolor, tanta termura,

conmuevan su honrosa tiranía.

No el estrago recela la porfía

de tu sentida peria, si procura:

menos semsible, hacer la desventura

que futal tc acompaña en ese día.

Mas, ¿̨quién te acusa? ¿qué delito priede

conducirte a ocasión tan lamentable

que a la impiedad mayor sin duda excede?

¿Quién puede ser? La envidia, que insariable,

porque su encoro victorioso quede,

a la misma inocencia hace culpable.

\section{VII}

Del dolor, fiero Bóreas, azotadiz

la miserable nave de tu vida,

VI Marco Antonio (143-87 a.d. J.C.), partidatio de Sila, se dirige al Serrado para hacerles ver cómo viver dominados por la tirauía de Mario y Cinna, régimena que lo ha condenado a muerte.

VII Marco Antonio (83-30 a.c. J.C.). víctima de Octaviano, sc stricida en Alejandría, y ya moribundo se hace conducir frente a Cleopatra a la que jutenta consolar. la diosa Aurora.

Vid. Soneto III. Bóreas: clios de los vientos del Norte, hijo del Titán Ascreo y de 
¡oh, Marco Antonio! sólo es tu guarida

la dulce vista de Cleopatra amada.

Ráfaga es el suspiro en que anegada

se mira la esperanza más sufrida,

y el triunfo de Octaviano, sumergida, tiene la chusma sin valor de nada.

Sin otro governalle que la queja, surcas las ondas de tu infeliz suerte; el mal se te avecina, el bien se aleja.

El Céfiro se muda en cierzo fucrte; sólo a tu amor alivia el ver que deja heredera a Cleopatra de su muerte.

\section{VIII}

Mal sufrida Popea, en la mudanza de su amante Nerón, fiel se lamenta, y cuanto más su afecto representa, tanto menos su amor alivio alcanza.

Perdida ya del todo su esperanza. cada voz que promulga es una afrenta, mas, ¿qué mujer contuvo lo de atenta si la contrastan celos y privanza?

Si a todo un vulgo miras suplicante por Octavia, ¿qué vale tu lamento cuando aquel monstruo no salió triunfante?

Deja el dolor, anima el sufrimiento. y pues sabes las leyes de lo amante, sírvate esta mudanza de escarmiento.

"Chusmet: aCente baja, soez c iúntil (Diccioncuró de Antoridades). Palabra muy utilizada por Mignel Egual en las Declamaciones. " Gobemalle. Timón de la nave. "H Frasc ambigua por la confusión entre la segunda y tercera pcrsona. Los dos adjetivos posesivos (su, tu) tienen un mismo referente, Marco Antonio.

Vill Popea se lamenta portguc su amante Nerón pretende regresar a los brazos de su esposa, e intenta recenerlo pero fracasa. 
Vana imaginación, dorado engaño, cruel esfinge, fantasía fiera, veneno oculto, ilusión severa, fugaz remedio, apetecible daño,

en fin, privanza que con modo estraño

despeñas al que sigue tu carrera brindándole finezas, porque muera antes que a lograr llegue el desengaño.

Experiencia infeliz de tus rigores Seyano es, y ejemplo a los mortales, para que así conozcan sus errores.

Adviertan consecuencias tan fatales: veráin que sólo serían tus favores, en vez de bientes, indecibles malcs.

\section{$\mathrm{X}$}

¿Sois otro que peligro apetecido, ¡oh, riquezas! y cterna pesadumbre? ¿Es vuestro logro más que servidumbre, continua inquietud, bien fementido?

Tal ves vuestro halago seducido piensa lograr la más cxcelsa cumbre quicn os posee, siendo cauta lumbre, que a sus reflejos queda entorpecido.

¡Oh, Séneca Prudente, qué fundadád arguye tu moral filusofía!

¿De qué to sirve carga tan pesada?

IX Elio Seyano, favorito y ministro de Tiberio, a quicn intentó destronar, es descubierto y condenaclo a muerte.

it Las dos frases rle este terceto remarcan la función conativa al hacer un llamamiento al lector, para que se persuada del equivoco comportamiento de Seyano.

X Cayo Ánco Séneca era envidiado por su riqueza y éj, consciente de ello, intenta razouar su situación para usí conseguir seguridad hacia su perbona.

${ }^{7}$ En el texto «cumbres. Error corregido en fe de erratas. 
Renuncia tan amable tiranía, que sólo puede ser riqueza amada la que induce quietud su compañía.

\section{XI}

Valerosa matrona que entre el llanto haces de tu heroico aliento fuerte heronía, que aún del descontento formas plausible, armonioso canto.

De esfuerzos nobles vistes el quebranto, en acordes transformas el lamento y haciendo victorioso el sufrimiento, aún de la misma pena eres espanto.

El dolor de tus hijas se consuela, Darío en su empresa nuevo aliento cobra, tu valor de Alejandro se cautela.

Todo espíritu débil se recobra: que en los trabajos la mayor escuela, es tener fortaleza en la zozobra.

\section{XII}

¿Dónde están, ;oh, Alejandro!, los trofeos de los más belicosos admirados? ¿Dónde tan vastos Reinos conquistados y aún corto el mundo todo a tus deseos?

¿Quién te ha incitado a tales devaneos? ¿Quién así ha pervertido tus cuidados? Mataste a Clito que entre los amados lograba el mayorazgo en tus empleos.

XI Sisigambe, mujer de Darío, se encuentra presa con sus hijas uras la derrota de éste. Su carácter de heroína familiar se manifiesta interviniendo, de modo fingido, con el fin de lograr el consuelo de los suyos en tan trágicas circunstancias.

"Curioso terceto formado por tres proposiciones yuxtapuestas que coinciden con las tres unidades versales. ${ }^{11}$ Claro ejemplo de soneto con esquema conclusivo, coronado con un llamamiento moral.

XII Alejandro, ebrio, no pudiendo soportar las críticas de su amigo Clito le da muerte. Más tarde, arrepentido de su acción, y ya sereno, intenta suicidarse, pero los guardias se lo impiden.

+ Ha de sobreentenderse el verbo "sers. Este cuarteto expresa el tópico del Ubi sunt. 
Toda tu fortnleza, hecha ternura, las granjeadas glorias fiel lamenta:

hasta el aliento su dolor procura.

¡Ol, intempcrancia! Envilecida afrenta:

¿Quién tc apetece, si obliga tu locura

a que el mismo Alejandro se arrepienta?

\section{XIII}

Al misno Cipión viste vencido

que hoy triunla de tu amada, ficl Cartago;

Ticio Sempronio padeció su estrago

al ardor de tu brazo enfurezido.

De Flaminio el aliento ya perdido, aún le lamenta el Trasimeno lago, y toda Roma a tu menor amago advirtió su valor todo oprimido.

Cantóse la fortuma fencntida permitiendo que así liegues a verte, a que al Romano ruegues te convida.

Eso no, Aníbal, valeroso y fucrte:

¿Lá patria esclava? ¿Para qué la vida?

¿La libertad perdida? ¿Qú́ más muerte?

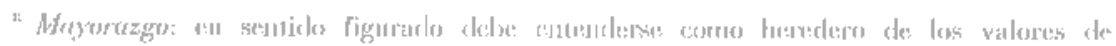
Alcjaurlors.

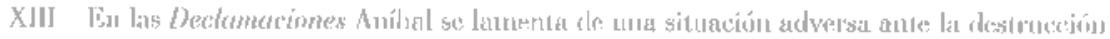

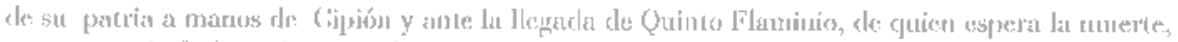
puesio duc Anibial mató a sir parlue.

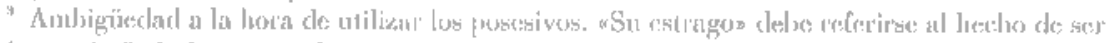

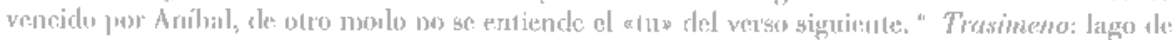

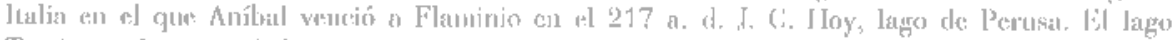

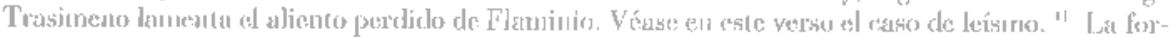

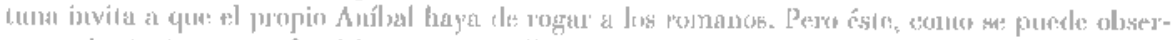

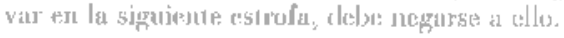


Valiente Campeón, Ciro animoso que vinculas tus glorias a tu espada, creyendo no es victoria bien ganada, la que se consiguió con tu reposo.

Hasta el mismo valor está celoso viendo que estimas a tı vida en nada, y que la fama, sólo de ti amada, no te permite estar un punto ocioso.

La amistad de Clearco no es hastante

a sosegar tu reflexión prudente:

A su celo le niegas el semblante.

Pues sólo consideras permanente aquella gloria, que al ardor constante deja de ti memoria eternamente.

\section{XV}

Tímida Roma al tragadero horrible que así amenaza su total ruina, no sabe resolver ni determina, modo como aplacar su horror terrible.

Curcio, que de su Patria el infalible daño previene, amante se destina al sacrificio, pues su amor le inclina a superar un mal tan indecible.

El Oráculo, la cosa más amada de Roma, dice que ha de ser perdida, y a esta boca feroz sacrificada.

XIV Giro pretende convencer a suts consejeros de aque para ser vencedor hay que participar en la batalla. Éstos, temerosos de perderle, sc resisten hasta ser convencidos.

* En el texto avíctima. Corregido en fe de erratas.

XV Eil la declamación, Tacio reprenkle la actítud de Mecio Curcio porque, sin haber razonado, se somete a los rigores del (tráculo y se despeña en sacrificio por ma tragadera que anenazaba el suelo de Roma. El Soneto transcumre de un modo narrativo y, curiosamente, alaba el pretendido heró́sno de Curcio. 
Siendo tu vida, pues, Ia más querida. sea con ella tu Patria libertada, consigues con tu muerte eterna vida.

\section{XVI}

Tus lágrimas hermosas, bella Elena, la impiedad conmovieran más tirana; mas, jay! que verse tu deidad humana, ¿quién duda que a delito la condena?

Quéjase Grecia al son de la cadena que le previene la crueldad troyana, todo por tu belleza, ;oh, inhumana! causa fatal de tan sensible pena.

Tu amor, joh, Elena! a todas luces ciego los males de tu Patria infiel procura: el Asia toda es un desasusiego.

y pues furiste de tantos desventura logren por tu herrnosura su sosicgo: será una vez dichosa la hermosura.

\section{XVII}

Si en los brazos de Paris, hado impio, me consigno con modo tarı violento, ¿qué culpá tuvo de mi amor lo atento, si fue un involuntario desvario?

A delito condenas un desvío que a ocupar no llegó el entendimiento, y quieres, Menelao, que el tormento padezca de un error que no fue mío.

XVI En las guerras de Troya los griegos envian a Uilises para (jue solicite a Príamo el regreso de Elena a su patria. Ésta, esposa del rey griego Menelao, ama a Paris con el que se la refugiado en Troya y no quiere volver a Grecia temiendo por su vída.

XVII Este soneto es temáticamente continuación del anterior. Tras la guerra de Troya, Elena es entregada a su esposo Menelan, ante el que intenta justificar sus deslices amorosos con Paris. 
Mira cómo el destino, que inculpable reconoce mi amor, a ti me entrega:

mi inocencia te advierte indisputable.

Mas, ¿quién fortuna a comprenderte llega, si es tu distribución tan variable que a todas luces se contempla ciega?

\section{XVIII}

Entre las ansias de una amarga muerte pelea de Germánico la vida, su mérito es tan sólo el homicida que aún hasta el merecer tiene su suerte.

De Pisón y Plancina el dardo fuerte hace mortal tan execrable herida; mas, joh, ambición! vileza envejecida en quien tus apariencias bien no advierte

$\mathrm{Al}$ paso que de todos venerado hoy se ve de sí mismo aborrecido: aumenta su dolor lo más amado.

Pues cuanto más sujcta lo sentido. excita a nueva pena su cuidado lu traición que a morir le ha conducido.

\section{XIX}

¿Hasta dónde tu espada valerosa quiere llegar de triunfos?

Sin duda a la fortuna desairada dejar pretende acción más ambiciosa.

¿No blasona los timbres de gloriosa logrando tanta tierra conquistada?

XVIII Pisón y su esposa Plancina, incitados por Seyanno y Tiberio, envenenan a Germánico. Éstc, antes de morir se dirige a su familia y amigos.

XIX En las Dectamaciones, Pirro, rey de los epirotas, es criticado por Cineas, ministro y consejero suyo, el cual le expone los inconvenientes de su espritu bélico y de sus afanes de conquista. 
Pues, ¿̨a qué aspira? ¿̨a hacerse desdichada?

esto conseguirá por codiciosa,

Mira a Cineas, Pirro, que elocuente.

las glorias de la vida considera:

su mismo amor te excita a lo prudente.

Detén a tu fortura la carrera

(uie si hoy te asiste favorablemente,

mañana puede convertirse en fier'a.

\section{$\mathrm{XX}$}

Teme Rosana y al mismo tiempo espera efectos de un amor fino y constante; espera en Alejamdro que os su manante; teme cuando su estado considera.

La esperanza su llama hace severa; e.] trmor la sosprende cada instante y entre tanta modestia vácilante. ni lía su amor, ni desespera.

Iua distancia que adviertes, ;oh, Rosana! es único motivo de tus males: termes tu dicha por la soberana.

No al ver extremos: pues, tan desiguales, desmaye tu belleza, más que humana. poryue les sabe amor hacer iguales.

\section{$\mathrm{XX1}$}

Howor de Tebas, Teágenes discreto, fue al ver Frine Lasciva lo que interita, 116) pudiendo sufrir tan grave afrenta, tu mismo pundonor te trae inquieto.

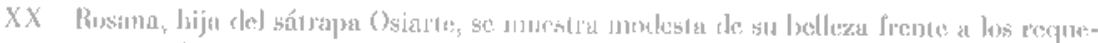

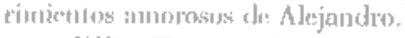

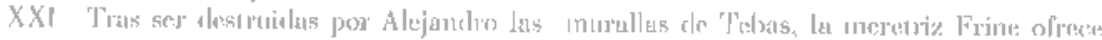

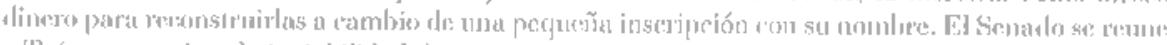

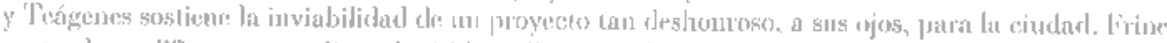

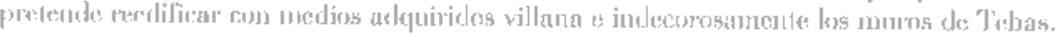


Al valor de Alejandro tu respeto

cede gustoso, porque si, violenta,

la fortuna inleliz su saña ostenta, mal pucde resistirse su decreto.

Tus muros Tehas, Frine, destruidos, reedificar pretende con villanos, indecorosos medios adquiridos.

¿Dónde está vuestro crédito, tebanos?

muros a liviandades erigidos, ¿qué fuertes potrán ser, si son livianos?

\section{XXII}

De la lasciva Frine, libre quedas, Cenócrates el siempre inalterable, sin que de su belloza lo agradable ser incentivo a su apetito puedi.

La parte superior es la que veda al la inferior tropiezo tan notable y cuanto puecle serle perturbable a su homesta constancia hace que ceda.

¡Oh, Filósofo invicto! ¿Quión no aspira a seguir inflexilble tu sentencia? ¿Quiéu de su fundamentos se retira?

Pues mos enseña con eficaz cimcia, que aún contra sí mismo se conspira, quien huye de la amable continencia.

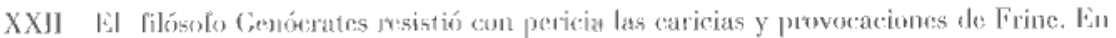

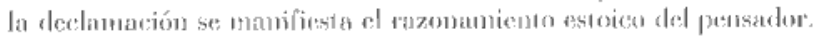




\section{Bibliografut}

- Enrique Blitrán Manisuple, Almazora. El Mijares. Nartación Histórtea. Castellón. 1958.

- Juan Buay Navarbo, Documentos y datos para la Historia de la ciudad de Olina. Valencia, Ecir, 1960.

- Migurel Figliar Corters, en la Bibliotera Serramo Motales de Valencia (BSM): 7.26417 (A-15) de la 3.907 a la 3,908; y m el Areténo del Colegio del Patriareha de

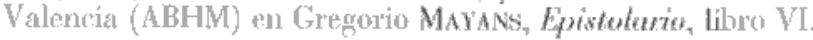

- Mignel Ecila, (tradnctor de): Juan Francisco Loredano, Dedanaciones Crendales, su Autor -, Noble vemeziamo. En Valencig, por Anonio Bordazar, 1731. Induye los 22 sonetos. Biblioteca de la Universidad de Valencia $(\mathrm{BL} T \mathrm{~V}): \mathrm{X}-6 / 02$.

- Juan Antonio EG:AL, Comers. BSM: 7.264-17 (A-15); 3.962-3.960.

- Pasqual Mas I Isos, «Mignel Egual, traductor i poetas, en La Fila-roja (narȩ, 1988).

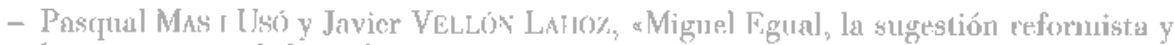
los imperativos de lá tradicións Actes del $/ 1$ congrés d'historia i Filologia de la Plank. Nules, abril de 1990, Nules, 1992, páğ. 149-161.

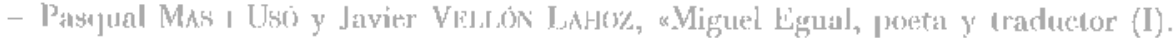

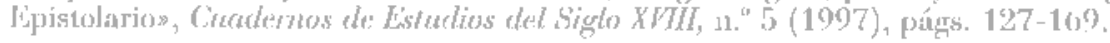

- Antenio Mrstre, El mundo intelecturl de Mayans, Valencia, Publicatciones del Ayuntamiouto de: Oliva, 1978.

Fernaudo Mundina, Histora, geografia y estadistica de la promincia de Castellón, (ásitellón, 1873.

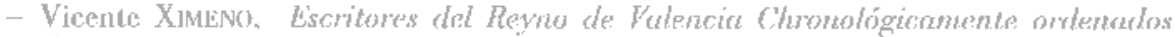

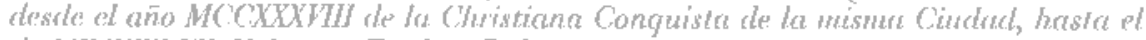

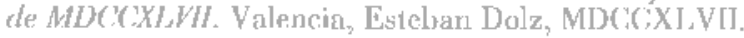

